\title{
Original Research \\ Evaluation of the suitability of potato cultivation areas in South Korea based on climate and soil conditions
}

\author{
Joon-Yong Shim ${ }^{1,2, \dagger}$, Jae-Min Jung ${ }^{2, \dagger}$, Wang-Hee Lee ${ }^{2,3, *}$ \\ ${ }^{1}$ Department of Digital Agriculture, Rural Development Administration, 54875 Jeonju, Jeollabuk-do, Republic of Korea \\ ${ }^{2}$ Department of Biosystems Machinery Engineering, Chungnam National University, 34134 Daejeon, Republic of Korea \\ ${ }^{3}$ Department of Smart Agriculture Systems, Chungnam National University, 34134 Daejeon, Republic of Korea \\ *Correspondence: Wanghee@cnu.ac.kr (Wang-Hee Lee) \\ $\dagger$ These authors contributed equally. \\ Academic Editor: Graham Pawelec \\ Submitted: 22 December 2021 Revised: 24 January 2022 Accepted: 25 January 2022 Published: 17 February 2022
}

\begin{abstract}
Background: Changes in dietary patterns have led to a decrease in rice consumption, raising demands for the cultivation of alternative crops that meet the current requirements. Potatoes are highly productive and can be stored for a relatively long period, thereby ensuring adequate income for farmers; however, optimal cultivation is necessary to maximize yield. Objective: This study proposes optimal cultivation regions for potato considering climate and soil conditions. Materials and methods: The CLIMEX model was developed to evaluate climatic suitability, while the soil suitability was scored based on five soil characteristics. The final areal suitability for potato cultivation was classified into 4 levels: very suitable, suitable, marginal, and unsuitable. Results: Overall, 36.5\% of South Korea had very suitable climate, but areas with the best values for soil conditions were approximately $10 \%$ of the climatically suitable areas. When considering the climate and soil conditions simultaneously, climatic suitability and soil condition were inversely related, resulting in only $1.2 \%$ of optimal areas with Jeju Island as the most suitable area. Conclusions: Because both climate and soil conditions need to be suitable for growing crops, this study can provide potential paddy-cultivation areas for potato cultivation and a method for evaluating suitable areas for crop cultivation.
\end{abstract}

Keywords: CLIMEX; potato; climatic suitability; soil suitability; suitable cultivation area

\section{Introduction}

Annual rice consumption in South Korea and other rice cultivation areas have consistently decreased due to climate change, and changes in household eating habits [1]. Overall, arable land utilization has steadily decreased since 1970 , leading to cultivation areas constituting only $16.9 \%$ of the total land area [2,3]. However, there is a disparity between rice supply and demand because of an increase in rice production. Hence, there has been an effort to flexibly use paddy fields for stable rice supply and enhance food self-sufficiency by producing (or rotating) other crops in paddy fields [4]. For example, feed value, harvesting time, and sowing period were compared under forage cropping systems $[5,6]$. Other studies of cropping systems investigated productivity and income of potato-corn in fields and paddies [7], sesame seed [8], and optimal forage crops in paddy fields in summer and winter [9]. Potential areas for apple cultivation have also been investigated $[10,11]$. Moreover, suitable areas for growing Italian ryegrass have been predicted in Gangwon-do [12] using a spatial distribution model [13]. Because climate change affects crops and their cultivation area [14], suitable growing areas have been identified for southern-type garlic [15], black raspberry [16], and teff and barley [17]. In this analysis, a geographic information system (GIS)-based analytic hierar- chy process was used [16,18]. Studies concerning uplandpaddy rotation has evaluated the effect of growth and yield on reclaimed tidal land [19], and on foxtail millet, proso millet, sorghum, and rice [4].

Various alternative crops for rice have been proposed, such as sweet potatoes, potatoes, and corn [14]. Among them, potatoes are favored as an alternative crop for rice by farmers because of advantages of relatively easy cultivation, long-term storage capacity and high productivity. Nevertheless, both quantity and quality of potatoes are greatly affected by climate and soil conditions [2,20,21]. Hence, it is necessary to consider both these factors while identifying potential areas for potato cultivation.

The CLIMEX model, a species distribution modeling tool specialized for climate-based prediction, can project potential distributions of a species by identifying climatically suitable areas [22-24], and has been widely applied to predict the climatic suitability of plants such as prickly acacia [25], common bean [26], and potato [27,28]. Soil suitability for crop cultivation is known to be a function of variables that define texture, drainage class, and slope $[11,12]$. A previous study predicted suitable cultivation regions for medicinal plants [29], while [30] reported major environmental factors affecting the geographical distribution and quality of Scutellaria baicalensis. In addition, 
there are some studies which predicted suitable areas for plant inhabitation, such as Panax notoginseng under various climatic conditions [31], habitat suitability modeling of Perilla frutescens [32], and prediction of current and future cultivation areas of Carthamus tinctorius [33].

The suitability of climate and soil for potato cultivation in South Korea can be evaluated using the CLIMEX model and the maximum limiting characteristic method [34]. This study aims to investigate the suitability of the climate and soil of paddy-cultivation areas for potato cultivation, and to propose an optimal area for field potato cultivation in South Korea based on the evaluation.

\section{Materials and methods}

\subsection{Description of the study area}

South Korea is geographically located in the midlatitude temperate zone $\left(\mathrm{N} 33^{\circ}-\mathrm{N} 39^{\circ}\right)$ with cold-dry winters, and hot-humid summers. The annual temperatures are measured from approximately -6 to $26^{\circ} \mathrm{C}$ during the year with the average annual temperature of $10-15^{\circ} \mathrm{C}$ [35]. The annual precipitation is approximately ranged from 1000 to $1900 \mathrm{~mm}$, while 50 to $60 \%$ of the precipitation occurs in summer [35]. In general, topography of South Korea can be divided into mountainous areas, hilly areas, mountain foot slopes, grain areas, alluvial fan areas, and flat areas. However, the topography is highly complex and the soil characteristics are also varied by areas [36].

\subsection{Soil data acquisition and processing to calculate the soil suitability}

Five soil variables were used to determine the soil suitability $\left(\mathrm{N}_{1}\right)$ for potato cultivation: soil texture, drainage class, slope, effective soil depth (the depth to which the roots can potentially extend), and gravel content. The data were obtained from the National Spatial Data Infrastructure [37] in polygon format. Data for five soil variables were determined and extracted using a $1 \mathrm{~km}$-grid coordinate system (140,237 points) process using ArcGIS (version 10.4.1, ESRI, Redland, CA, USA), and the extracted points were converted into a raster format. Consequently, a spatial database recording values for five soil variables with a $1 \mathrm{~km}$ resolution in South Korea was constructed to calculate $\mathrm{N}_{1}$. The values were then used to score the suitability for potato cultivation based on the criteria provided by the Rural Development Administration (RDA) in South Korea $[38,39]$ (Table 1). $\mathrm{N}_{1}$ was calculated using the spatial analysis tool in ArcGIS by summing the scores of five soil variables with a maximum value of $100 . \mathrm{N}_{1}$ was classified into four grades according to the soil survey manual [38]: very suitable $(\geq 85)$, suitable (80-84), marginal (70$79)$, unsuitable $(\leq 69)$, and impossible $(=0)$ (Table 1).

\subsection{Climate suitability using the CLIMEX model}

The CLIMEX (version 4.0, Hearne software, Australia) model predicts the potential distribution of a target species based on meteorological information and estimated model parameters from biological information. The possibility of species distribution is quantified using the Ecoclimatic Index (EI), which is a representative of climatic suitability resulting from the growth index (GI) and stress index (SI) $[22,40]$. Potatoes are generally not exposed to stressful climates because they are predominantly cultivated in favorable climates. Hence, the EI for potato was determined based only on the parameter related to GI, meaning that EI and GI values were the same, because SI could not be calculated for potato. Thus, climatic suitability $\left(\mathrm{N}_{2}\right)$ was classified using the GI values. A GI value of 50 is the general maximum value in the CLIMEX model and indicates a favorable climate sustained during the six-month cultivation period. A GI value of 25 (for growth over three months) was considered to be the best for potato growth in South Korea because potato generally requires three months after sowing seed potato [41]. Consequently, we classified $\mathrm{N}_{2}$ into five categories; very suitable (GI $\geq 25)$, suitable $(25>\mathrm{GI} \geq$ $20)$, marginal $(20>\mathrm{GI} \geq 10)$, unsuitable $(10>\mathrm{GI} \geq 1)$ and impossible conditions $(\mathrm{GI}=0)$ to grow the potato in paddy fields. The details of the operation of the CLIMEX model are described in [22] and [40]. The climate variables were obtained from WorldClim (http://worldclim.org/version2) (monthly maximum temperature, minimum temperature, and rainfall with $1 \mathrm{~km}$ spatial resolution) [42], and were clipped to fit for South Korea.

\subsection{Parameter estimation of potato to use CLIMEX model}

Temperature Index (TI), Moisture Index (MI), and Light Index (LI) were among seven indices necessary for calculating GI, and were used by considering data availability. In addition, CLIMEX calculates minimum degreedays required to complete a generation by using a parameter of population degree day (PDD). TI has four parameters from DV0 to DV3, and DV0 and DV3 designate the lower and upper threshold temperature of the target species. MI includes four parameters from SM0 to SM3, representing the lower and upper threshold soil moisture, respectively, and determined by the amount of precipitation in a specific area. The CLIMEX parameters of potato were employed from a previous study [24], and adjusted for the growing conditions for major Korean potatoes such as Superior, suggested by the RDA [30] (Table 2). The RDA reported that the suitable temperature range for growing potato was $14-23{ }^{\circ} \mathrm{C}$, with a suitable daytime temperature of 23-24 ${ }^{\circ} \mathrm{C}$. Therefore, the lower optimal (DV1) and upper optimal (DV2) temperatures, which encode the optimal temperature range for species growth, were set to $14^{\circ} \mathrm{C}$ and $24^{\circ} \mathrm{C}$, respectively, while the limiting high temperature (DV3) was adjusted to $30{ }^{\circ} \mathrm{C}$, which inhibits the obesity of the tuber. In South Korea, potato growth has been affected by droughts and flooding in the spring and summer, respectively. Hence, the parameters related to soil moisture were modified based on the relationship between potato produc- 
Table 1. Standard soil suitability values for potato from the soil and environmental information system of the Rural Development administration.

\begin{tabular}{|c|c|c|c|c|c|}
\hline Soil characteristics & Grade & Poor (5) & Normal (10) & Proper (15) & Good (20) \\
\hline Soil texture & & Sandy & Clayey & $\begin{array}{c}\text { Clay loam } \\
\text { Silty clay loam }\end{array}$ & $\begin{array}{c}\text { Sandy loam } \\
\text { Silty sandy loam }\end{array}$ \\
\hline Drainage class & & Poor & Excessively well & Moderately & Well \\
\hline Slope (\%) & & $>15$ & $7-15$ & $2-7$ & $0-2$ \\
\hline Effective soil depth $(\mathrm{cm})$ & & $<20$ & $20 \sim 50$ & $50 \sim 100$ & $>100$ \\
\hline Gravel content $(\%)$ & & $>35$ & & $<10$ & $10-35$ \\
\hline
\end{tabular}

Table 2. Parameter values used for potato in CLIMEX.

\begin{tabular}{lccc}
\hline Parameters & Code & Previous values & Adjusted values \\
\hline Temperature & & & \\
Limiting low temperature $\left({ }^{\circ} \mathrm{C}\right)$ & DV0 & 4 & 4 \\
Lower optimal temperature $\left({ }^{\circ} \mathrm{C}\right)$ & DV1 & 16 & 14 \\
Upper optimal temperature $\left({ }^{\circ} \mathrm{C}\right)$ & DV2 & 25 & 24 \\
Limiting high temperature $\left({ }^{\circ} \mathrm{C}\right)$ & DV3 & 40 & 30 \\
PDD & & 950 & 950 \\
Moisture & & & \\
Limiting low soil moisture & SM0 & 0.05 & 0.2 \\
Lower optimal soil moisture & SM1 & 0.2 & 0.4 \\
Upper optimal soil moisture & SM2 & 0.8 & 1.6 \\
Limiting high soil moisture & SM3 & 1.5 & 2.5 \\
Light & & & 10 \\
Daylength at no growth & LT1 & 10 & 16 \\
Daylength at maximum growth & LT0 & 16 & \\
\hline
\end{tabular}

tion and seasonal precipitation in South Korea. In detail, the parameters of SM were set for Gangwon-do, the region with the highest production of wild potatoes, and we assumed that the amount of precipitation in that region was optimal for potato cultivation. The SM parameters were adjusted by setting SM0 to SM3 as the minimum and maximum precipitation in Gangwon-do. Finally, we verified the potential distribution comparing the regional capacity of potatoes in administrative district and GI value.

\subsection{Assessment of suitability to cultivate potato}

The final suitable sites for cultivation of potato $\left(\mathrm{S}_{n}\right)$ were classified into four categories by simultaneously considering $\mathrm{N}_{1}$ and $\mathrm{N}_{2}$ : very suitable $\left(\mathrm{S}_{1}\right.$ : both $\mathrm{N}_{1}$ and $\mathrm{N}_{2}$ were very suitable), suitable $\left(\mathrm{S}_{2}\right.$ : either $\mathrm{N}_{1}$ or $\mathrm{N}_{2}$ were suitable or above), possible $\left(\mathrm{S}_{3}\right.$ : either $\mathrm{N}_{1}$ or $\mathrm{N}_{2}$ were marginal or above), and unsuitable $\left(\mathrm{S}_{4}\right.$ : either $\mathrm{N}_{1}$ or $\mathrm{N}_{2}$ were unsuitable or above). We concluded that locations where potato cultivation was impossible did not exist in South Korea, as it only accounted for approximately $10^{-6}$ percentage of the total area.

\section{Results and discussion}

\subsection{Soil suitability for potato}

The crop yields are related to physical properties of the soil, and they affect growth differently depending on the crop [43]. Even for the same variety, potatoes show differences in growth and quality depending on the soil type, and are sensitive to climate, suggesting the necessity for proposing areas for its cultivation by considering both climatic and soil conditions [44].

Among the soil variables, soil texture had the highest value, with an average of 17.3 , whereas the slope showed the lowest average score of 8 (a high value means that there are many suitable areas for growing potatoes). Approximately $90 \%$ of the soil texture at the calculated suitability points was either optimal or suitable, while only $1.2 \%$ of the area was scored as inadequate (Fig. 1A, Table 3). In general, plant length and yield have been reported to be long and high, respectively, in the order clay loam, loam, and sandy loam $[45,46]$. Considering the above criteria, South Korea had a very suitable environment for potato cultivation; in this study, approximately $50 \%$ of the regions were found to be sandy loam. In addition to potatoes, soybean [47], broadleaf liriope [48], Asian lizard's tail [49], and sesame 
Table 3. Ratio of areas to cultivate potato for different soil and climate conditions.

\begin{tabular}{|c|c|c|c|c|c|c|}
\hline Factors & $\begin{array}{l}\text { Ratio of optimal } \\
\text { area (\%) }\end{array}$ & $\begin{array}{c}\text { Ratio of suitable } \\
\text { area }(\%)\end{array}$ & $\begin{array}{c}\text { Ratio of marginal } \\
\text { area }(\%)\end{array}$ & $\begin{array}{c}\text { Ratio of unsuitable } \\
\text { area }(\%)\end{array}$ & $*$ Ratio of etc. $(\%)$ & $\begin{array}{l}\text { Average score of } \\
\text { suitability (SD) }\end{array}$ \\
\hline Drainage class & 32.3 & 7.6 & 45.7 & 10.8 & 3.6 & $13.2(5.3)$ \\
\hline Texture & 49.7 & 40.4 & 4.1 & 1.2 & 4.6 & $17.3(3.2)$ \\
\hline Effective depth & 18.2 & 37.8 & 21.8 & 18.6 & 3.6 & $12.9(5.0)$ \\
\hline Gravel contents & 31.7 & 34.8 & - & 29.9 & 3.6 & $13.6(6.1)$ \\
\hline Slope & 9.0 & 10.9 & 11.0 & 65.5 & 3.6 & $8.0(5.0)$ \\
\hline Growth Index & 37.6 & 45.7 & 16.7 & $<0.1$ & 0 & $23.1(3.7)$ \\
\hline
\end{tabular}

* This ratio means that proportion not analyzed in the model.

a

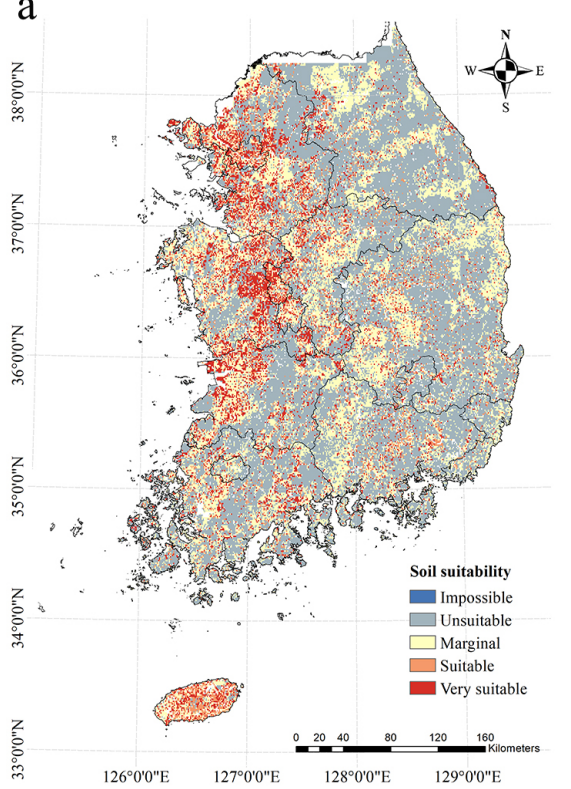

b

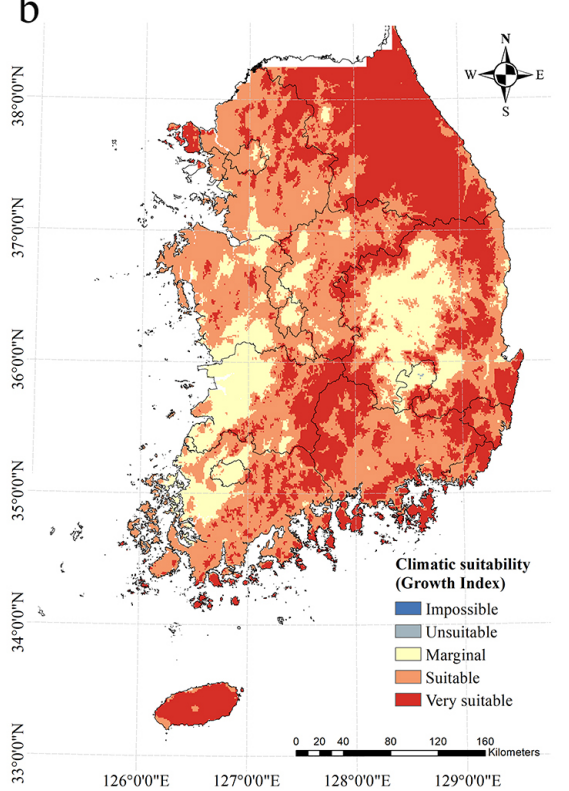

$\mathrm{c}$

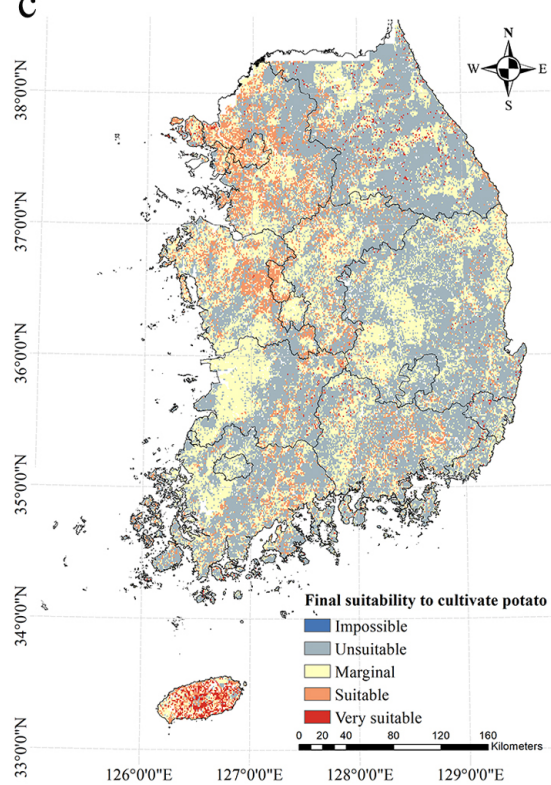

Fig. 1. Maps showing (a) soil, (b) climate, and (c) soil + climate suitability for cultivating potato.

[50] grow well in sandy loam soils, indicating that South Korean soil is suitable for cultivating various crops. In contrast, the values for slope indicated unfavorable conditions; high slopes are unsuitable for potato cultivation. Approximately $65 \%$ of the areas scored based on the slope were evaluated to be unsuitable, while $20 \%$ of the areas were above suitable. Consequently, $\mathrm{N}_{1}$ changed significantly with slope. A previous study also reported that the slope and elevation explain $22 \%$ to $36 \%$ variability of yield for potato tuber [51]. In addition, the slope was reported to be inversely correlated with the potato yield because of limited mechanization of field crops at a high slope, which was consistent with the current result. For this reason, it is necessary to cultivate potatoes in flat areas for high potato production $[52,53]$.

When analyzing the soil variable score and overall suitability, approximately $50 \%$ of areas in South Korea were classified as unsuitable for potato cultivation, while only $16 \%$ of the area was suitable or optimal. The Jeju-do region was found to have the best soil for potato cultivation (Fig. 2A). Jeju-do and Gwangju scored the best and worst drainage classes, respectively. In addition, Gwangju had the lowest score for soil texture in South Korea, while Sejong showed the highest score. The effective soil depth and gravel content were higher in Sejong than in any other region, but Daegu scored the lowest. A high gravel content may increase the incidence of physiological disorders in potato [54]. According to a previous study [39], reported that field crops yield high gravel content; suitable levels of gravel facilitate good drainage, which is advantageous for growth [55]. An effective soil depth is the depth at which crops can reach roots and absorb air, water, and nutrients [46]. Accordingly, the deeper the effective soil depth, the better the crop growth. In particular, the maximum yield was confirmed at $75 \mathrm{~cm}$ or more in sandy loam and 100 $\mathrm{cm}$ in loam and loam soil. However, at a lower effective soil depth, the soil volume for storing water and nutrients is small, resulting in poor growth of the roots and reduced yield [46]. For this reason, it is worthwhile to project a potential distribution of potatoes using effective soil depth and gravel content because high potato yield can be obtained with suitable site classified by the effective soil depth. In 

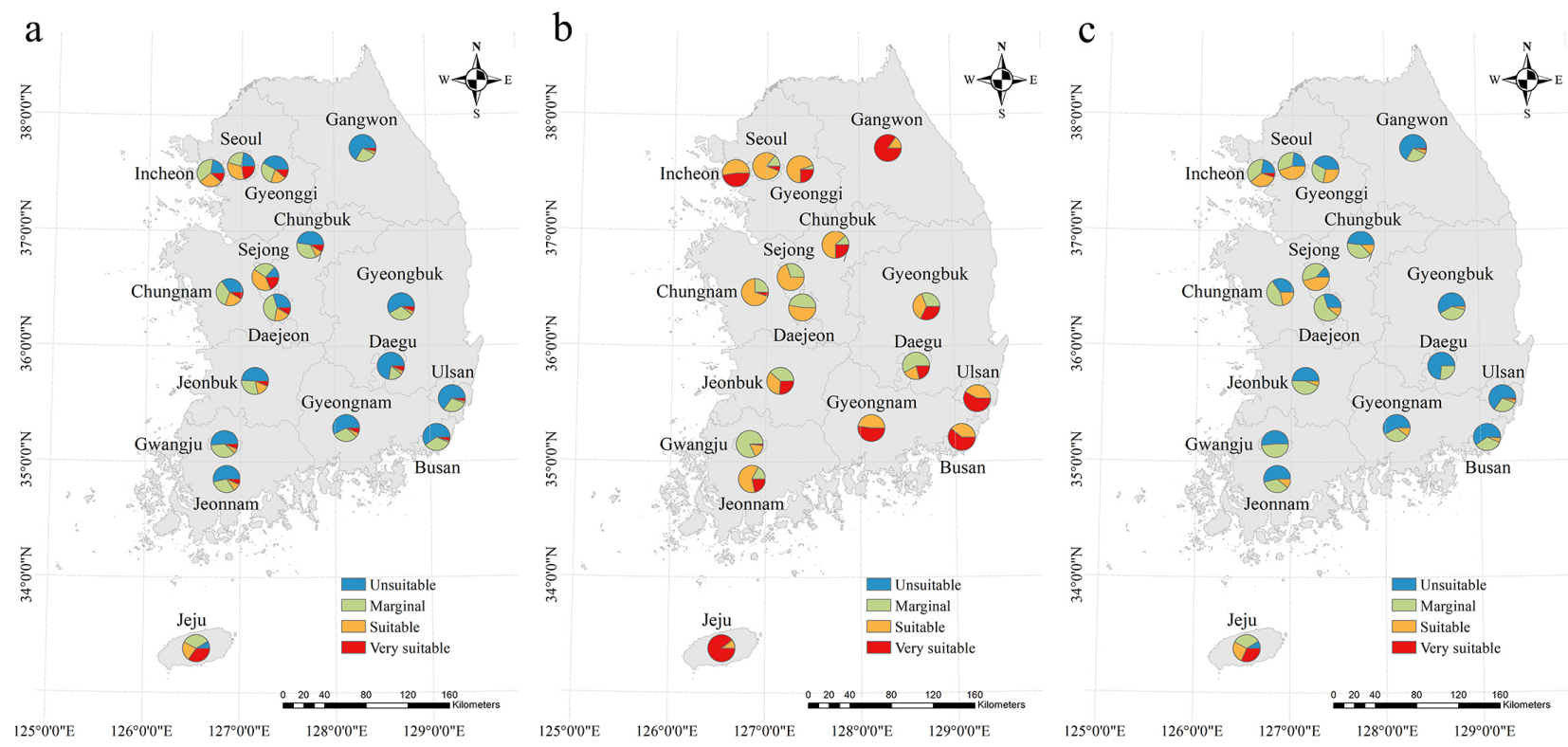

Fig. 2. Ratio of (a) soil, (b) climate, and (c) soil + climate suitability to cultivate potato in 17 administrative districts.

this study, an effective soil depth of more than $50 \mathrm{~cm}$ was found in $56 \%$ of the total area in South Korea, while in approximately $44 \%$ of the area, it was $50 \mathrm{~cm}$ or less. Incheon and Gangwon had the most and least suitable slope, respectively, for potato cultivation. In general, the soil conditions for potato cultivation were relatively more suitable in Sejong, Jeju-do, Incheon, and Seoul compared to other regions.

In terms of the ratio of suitable cultivation areas, the Jeju-do region, which scored the highest soil suitability, had $35 \%$ of the optimal areas for potato cultivation, while Ulsan, with $4 \%$ of suitable areas, had the lowest score. The ratio of suitable and marginal areas was high in Sejong and Daejeon, and the least favorable scores were mainly observed in the eastern region, including Daegu, which showed the lowest soil suitability for potato cultivation. In contrast, only $9 \%$ of the unsuitable areas were found in Jeju-do, which was the lowest score among the different regions in South Korea.

\subsection{Climatic suitability of potato}

Most regions in South Korea were predicted to be suitable for potato cultivation, particularly in regions with high elevation and low temperatures (Fig. 1B). However, the $\mathrm{N}_{2}$ of Gyeongsangbuk-do and Jeollabuk-do was relatively low compared to other provinces, suggesting that the climate might not be suitable for cultivating potatoes (Fig. 2B). Favorable values of $\mathrm{N}_{2}$ in South Korea were evaluated to be $36.5 \%$, mainly occurring in Gangwon-do and Jeju-do, where either suitable or marginal areas were $58.6 \%$, and unsuitable areas were less than $0.1 \%$ (Table 3 ).

Potatoes vary considerably in yield and quality depending on the environmental conditions, but the most influential factor is temperature [20,56,57]. However, it was reported that annually harvested crops, such as potato, rarely suffer from the effects of external temperatures as they grow only during climatically favorable conditions [58]. In this study, only GI was used to predict climatic suitability, excluding SI, because most of the potatoes were sown and planted at specific times, indicating that it is not generally exposed to external climatic stresses. In contrast, SI needs to be considered in addition to GI in wild plants (e.g., wild ginseng). Some crops are constantly exposed to unfavorable conditions, causing climatic stresses. In CLIMEX, an SI of 100 or higher indicates an impossible condition for plant grow, so SI can be useful for finding a suitable cultivation area even though it was not used in for potato due to the above reason.

Favorable scores for $\mathrm{N}_{2}$ in Jeju-do was approximately $90 \%$, which was the highest, followed by Gangwon-do (84\%), with the largest areal size $\left(14,173 \mathrm{~km}^{2}\right)$ (Fig. 2B). The regions with less than $5 \%$ scores for ratio of very suitable areas were Seoul, Gwangju, Daejeon, Sejong, and Chungcheongnam-do, which are located in the west. Even though the ratio of GI $\geq 25$ was low in Seoul, approximately $80 \%$ of the areas showed a suitable climate $(25>$ GI $\geq 20)$. In addition, Gyeonggi-do, Chungcheongnam-do, and Sejong were assessed to have a high level of suitable areas (approximately $70 \%)$. The ratio of the marginal $(20>\mathrm{GI} \geq 10)$ area was highest in Gwangju (approximately 80\%), while Gyeongsangbuk-do showed the widest marginal area (5890 $\mathrm{km}^{2}$ ). The unsuitable area only occurred in Daegu, but it was only $0.6 \%$. Collectively, temperature was expected to be very suitable for potato cultivation during summer in Gangwon-do, while it would be suitable for spring and fall in other areas. In addition, precipitation was found to occur throughout the country, but torrential downpour during the summer could drastically reduce the climatic suitability, 
proposing high flood damage in Gangwon-do and Jeju-do, where summer precipitation is higher than in other regions [59].

\subsection{Optimal cultivation areas based on climate and soil conditions}

The ratio of areas very suitable for potato cultivation based on climate and soil conditions $\left(\mathrm{S}_{1}\right)$ in South Korea was $1.2 \%$, with the highest value in Jeju-do, which showed $32 \%$ of suitable areas and the largest areal size of $388 \mathrm{~km}^{2}$ in Gangwon-do (Fig. 1C,2C). Conditions for $\mathrm{S}_{1}$ were not satisfied in 5 of the 17 administrative districts in South Korea, and $\mathrm{S}_{1}$ was less than $1 \%$ in 7 districts (Fig. 2C). The proportion of suitable areas $\left(\mathrm{S}_{2}\right)$ was $10.9 \%$, and they were mainly distributed in Seoul, Sejong, Gyeonggi-do, and Chungcheongnam-do, with a value of approximately $45 \%$ in Seoul and Sejong. In addition, marginal suitability $\left(\mathrm{S}_{3}\right)$ and unsuitability $\left(\mathrm{S}_{4}\right)$ were $33.2 \%$ and $49.8 \%$, respectively, suggesting that most of the South Korean regions were categorized into $\mathrm{S}_{3}$ and $\mathrm{S}_{4}$. Daejeon showed the highest value for $\mathrm{S}_{3}$ at $59.2 \%$, while $72.9 \%$ of Daegu fell into $\mathrm{S}_{4}$, which was the highest ratio throughout the country. In conclusion, more than half of the land in South Korea was not suitable for cultivating potatoes, largely because of the low soil suitability observed in approximately $50 \%$ of the country. Moreover, climatic and soil suitability was projected in opposite patterns, with few areas showing favorable values for both factors. Nevertheless, $\mathrm{S}_{1}$ was highest in the high-altitude region of Gangwon-do, which is consistent with the fact that it has the highest potato production capacity in South Korea [60].

Previous study established that there was considerable variation in crop cultivation to bioclimatic factors in current scenarios, showing direct influence on areas where potato cultivation in mountainous areas between 2000 and 4000 meters above sea level [61]. In South Korea, there was a region-wide difference in $\mathrm{N}_{2}$, but in most regions, it was suitable to cultivate potatoes at a specific time. Accordingly, it was predicted that in most regions, the plants would be more sensitive to soil conditions. In particular, because the area with $\mathrm{N}_{1}>85$ was only $10 \%$ of the area with $\mathrm{N}_{2}$ $>25, \mathrm{~N}_{1}$ would have a greater influence on the area of $\mathrm{S}_{n}$. Therefore, in the case of Korea, it may be desirable to select land for potato cultivation by first considering the soil conditions rather than climate.

Previous studies which predicted the growth, production, and distribution of potatoes were reported, such as global potential potato production according to climate change [27], and the potential amount of potato yield in suitable sites by seasons [62]. Most studies were modeled by analyzing climate and soil conditions [27,51,62], while this study related scores of five soil variables and the climate suitability of potatoes using CLIMEX. For this reason, we expect that this study provides detail information necessary for potato cultivation. In particular, since CLIMEX uses time-series climate data (monthly average temperature and rainfall), this result has demonstrated the climatic suitability of potatoes based on scientific evidence compared to the potential distribution of potatoes in previous studies $[11,13,27]$. For example, a previous study used annual climate data to confirm the potential distribution of potatoes [27], so it is difficult to obtain a dynamic potential distribution considering monthly variation of climates. In contrast, CLIMEX is a semi-dynamic model that calculates monthly temperature, precipitation, and duration of light to derive regional suitability of species, suggesting detail response to climatic condition compared to existing studies [22,27].

Climatic conditions in South Korea are known to be unfavorable for potato cultivation [63,64]. Rainy season begins at the harvest time for spring potatoes in South Korea, causing poor quality due to a high amount of precipitation, while heat damage during sowing time of autumn potato has been observed [63-65]. Similarly, this study evaluated that approximately $80 \%$ of regions were marginal suitable or unsuitable even though this study focused on geographic suitability rather than time-climate relationship during cultivation [28]. However, as this study used soil and climatic conditions which were major factor determining the suitable area of potato cultivation, the selected regions $\left(\mathrm{S}_{1}\right.$ and $\left.\mathrm{S}_{2}\right)$ suggests relatively suitable areas in South Korea when cultivating potatoes as an alternative crop.

\section{Conclusions}

A suitable area with high climate and soil suitability for crop cultivation is important to enhance crop productivity, and both factors must be considered for field cultivation. This study investigated suitable paddy-cultivation areas for the field cultivation of potatoes in South Korea by simultaneously considering climate and soil conditions. The current results proposed that optimal potato cultivation depended mainly on soil conditions rather than climate and Jeju Island as the most suitable area having the best climate and soil conditions in South Korea. This result can be used as information for selecting potato cultivation sites with less risk and high productivity to a farmer with fallow land. Even though non-environmental factors, such as economic concerns, transportation, and distance from local markets, must be taken into consideration to choose an optimal cultivation area, this study can function as a basic evaluation because climate and soil are the most important determinants. In the future, the aforementioned non-environmental factors may be included in the evaluation step so that the most optimal and practical potato cultivation areas can be proposed.

\section{Author contributions}

J-YS and J-MJ equally participated in the design, analysis, and writing the manuscript. W-HL supervised the study and revised manuscript. 


\section{Ethics approval and consent to participate}

Not applicable.

\section{Acknowledgment}

Not applicable.

\section{Funding}

This work was supported by the Rural Development Administration (RDA) (Grant number. PJ01533101) and the Basic Science Research Program through the National Research Foundation of Korea (NRF) funded by the Ministry of Science, ICT and Future Planning (NRF2021R1I1A3050757).

\section{Conflict of interest}

The authors declare no conflict of interest.

\section{References}

[1] Korean Statistical Information Service (KOSIS), Statistics Korea. Grain consumption. 2021. Available at: https://kosis.kr/statisticsList/statisticsListIndex.do?vwcd= MT ZTITLE\&menuId=M 01 01\#content-group (Accessed: 11 June 2021).

[2] Korean Statistical Information Service (KOSIS). 2021. Available at: https://kosis.kr/statisticsList/statisticsListIndex.do?vwc $\mathrm{d}=\mathrm{MT}$ ZTITLE\&menuId=M_01_01\&outLink=Y\&entrType =\#content-group (Accessed: 11 June 2021).

[3] Information and statistical Policy Officer, Ministry of Agriculture, Food and Rural Affairs(MAFRA) Food, agriculture, forestry and fisheries statistical yearbook. Ministry for food, agriculture, forestry and fisheries(MIFAFF). 2015. Available at: https://www.mafra.go.kr/mafra/358/subview.do?enc=Zm5j dDF8QEB8JTJGYmJzJTJGbWFmcmEIMkY2NSUyRjIzNDQ xNCUyRmFydGNsVmlldy5kbyUzRg\%3D\%3D (Accessed: 21 May 2021)

[4] Yoon ST, Jae EK, Kim YJ, Jeong IH, Han TK, Kim TY, et al. Growth and yield characteristics of foxtail millet, proso millet and sorghum according to sowing date in middle area in Korea. Korean Journal of crop science. 2015; 60: 197-211.

[5] Kim JD, Kim DA, Park HS, Kim SG. Effect of planting date and hybrid on forage yield and quality of corn for silage I. Agronomic characteristics and forage yield of corn. Journal of the Korean Society of Grassland and Forage Science. 1999; 19: 211220.

[6] Ju JI, Kang YS, Seong YG, Ji HC, Lee HB. Study on high forage production in double cropping systems with barley and corn at paddy field in middle region. Journal of The Korean Society of Grassland and Forage Science. 2012; 32: 285-292.

[7] Bae HH, Lee JS, Son BY, Kim JT. Comparison of yield potential and income of potato-maize cropping systems in paddy and upland field condition. The Journal of the Korean Society of International Agriculture. 2016; 28: 505-511.

[8] Nam SY, Kim IJ, Kim MJ, Kang HJ, Yun T, Rho CW. Effects of green manure crops and rotational cropping system on growth and yield of sesame (sesamum indicum L.). Korean Journal of Plant Resources. 2007; 20: 404-408.

[9] Kim WH, Shin JS, Lim YC, Seo S, Kim KY, Lee JK. Study on the promising double cropping system of summer and winter forage crop in paddy field. Journal of The Korean Society of Grassland and Forage Science. 2005; 25: 233-238.

[10] Seo HH, Kim JK. Cultivation of fruit trees in Korea under the changing climate. In: Proceedings of the Korean society of agri- cultural and forest meteorology conference. Korean Society of Agricultural and Forest Meteorology. 2005; 103-106.

[11] Kim SO, Chung UR, Kim SH, Choi IM, Yun JI. The suitable region and site for 'Fuji' apple under the projected climate in South Korea. Korean Journal of Agricultural and Forest Meteorology. 2009; 11: 162-173.

[12] Kim KD, Sung KI, Jung YS, Lee HI, Kim EJ, Najid JG, et al. Suitability classes for Italian ryegrass (Lolium multiflorum Lam.) using soil and climate digital database in Gangwon Province. Journal of the Korean Society of Grassland and Forage Science. 2012; 32: 437-446.

[13] Kim HA, Hyun SW, Kim KS. A study on the prediction of suitability change of forage crop Italian Ryegrass (Lolium multiflorum L.) using spatial distribution model. Korean Journal of Agricultural and Forest Meteorology. 2014; 16: 103-113.

[14] Lane A, Jarvis A. Changes in climate will modify the geography of crop suitability: agricultural biodiversity can help with adaptation. Journal of Semi-Arid Tropical Agricultural Research. 2007; 4: 1-12.

[15] Kim YW, Hong SY, Kim YH, Jang MW. Water balance-based farmland suitability for southern-type garlic cultivation. Journal of the Korean Society of Agricultural Engineers. 2012; 54: 19 28.

[16] Kim TJ, Lee GS. The site analysis for crop cultivation using GISbased AHP method. Journal of The Korean Society of Civil Engineers. 2006; 26: 695-702.

[17] Araya A, Keesstra SD, Stroosnijder L. A new agro-climatic classification for crop suitability zoning in northern semi-arid Ethiopia. Agricultural and Forest Meteorology. 2010; 150: 1057-1064.

[18] Mustafa AA, Singh M, Sahoo RN, Ahmed N, Khanna M, Sarangi A, et al. Land suitability analysis for different crops: a multi criteria decision making approach using remote sensing and GIS. Researcher. 2011; 3: 61-84.

[19] Oh YY, Kim YJ, Lee SH, Ryu JH, Kim S, Lee JT, et al. Effects of paddy-upland rotation on soil characteristics and crop productivity in rice fields on reclaimed tidal land. Journal of Environmental Science International. 2018; 27: 641-650.

[20] Kooman PL, Haverkort AJ. Modelling development and growth of the potato crop influenced by temperature and daylength: LINTUL-POTATO. Potato ecology and modelling of crops under conditions limiting growth (pp. 41-59). Dordrecht: Kluwer academic publishers. 1995.

[21] Jansky SH, Jin LP, Xie KY, Xie CH, Spooner DM. Potato production and breeding in China. Potato Research. 2009; 52: 57 65

[22] Kriticos DJ, Maywald GF, Yonow T, Zurcher EJ, Herrmann NI, Sutherst RW. CLIMEX Version 4: Exploring the effects of climate on plants, animals and diseases. Canberra: CSIRO. 2015.

[23] Jung JM, Jung SH, Ahmed M, Cho BK, Lee WH. Invasion risk of the yellow crazy ant (Anoplolepis gracilipes) under the Representative Concentration Pathways 8.5 climate change scenario in South Korea. Journal of Asia-Pacific Biodiversity. 2017; 10: 548-554.

[24] Byeon DH, Jung JM, Park YJ, Lee HS, Lee JH, Jung SH, et al. Model-based assessment of changes in the potential distribution of Solenopsis geminata (Hymenoptera: Formicidae) according to climate change scenarios. Journal of Asia-Pacific Biodiversity. 2020; 13: 331-338.

[25] Senaratne KW, Palmer WA, Sutherst RW. Use of CLIMEX modelling to identify prospective areas for exploration to find new biological control agents for prickly acacia. Australian Journal of Entomology. 2006; 45: 298-302.

[26] Ramirez-Cabral NYZ, Kumar L, Taylor S. Crop niche modeling projects major shifts in common bean growing areas. Agricultural and Forest Meteorology. 2016; 218: 102-113. 
[27] Hijmans RJ. The effect of climate change on global potato production. American Journal of Potato Research. 2003; 80: 271279 .

[28] Jung JM, Lee SG, Kim KH, Jeon SW, Jung SH, Lee WH. The potential distribution of the potato tuber moth (Phthorimaea Operculella) based on climate and host availability of potato. Agronomy. 2020; 10: 12 .

[29] Zhang L, Cao B, Bai C, Li G, Mao M. Predicting suitable cultivation regions of medicinal plants with Maxent modeling and fuzzy logics: a case study of Scutellaria baicalensis in China. Environmental Earth Sciences. 2016; 75: 1-12.

[30] Xu N, Meng F, Zhou G, Li Y, Wang B, Lu H. Assessing the suitable cultivation areas for Scutellaria baicalensis in China using the Maxent model and multiple linear regression. Biochemical Systematics and Ecology. 2020; 90: 104052.

[31] Zhan P, Wang F, Xia P, Zhao G, Wei M, Wei F, Han R. Assessment of suitable cultivation region for Panax notoginseng under different climatic conditions using MaxEnt model and highperformance liquid chromatography in China. Industrial Crops and Products. 2022; 176: 114416.

[32] Sharma S, Arunachalam K, Bhavsar D, Kala R. Modeling habitat suitability of Perilla frutescens with MaxEnt in Uttarakhand-A conservation approach. Journal of Applied Research on Medicinal and Aromatic Plants. 2018; 10: 99-105.

[33] Wei B, Wang R, Hou K, Wang X, Wu W. Predicting the current and future cultivation regions of Carthamus tinctorius L. using MaxEnt model under climate change in China. Global Ecology and Conservation. 2018; 16: e00477.

[34] Korean Soil Information System. National Institute of Agricultural Sciences. 2021. Available at: http://soil.rda.go.kr/soil/crop /CR032.htm (Accessed: 15 July 2021).

[35] Korea Meteorological Administration (KMA). 2021. Available at: https://www.kma.go.kr/weather/climate/average_south. jsp (Accessed: 21 May 2021).

[36] Korean Soil Information System. National Institute of Agricultural Sciences. 2021. Available at: http://soil.rda.go.kr/soil/soil act/characterize.jsp (Accessed: Day Month Year).

[37] National spatial data infrastructure portal (NSDI) 2020. 2021. Available at: http://www.nsdi.go.kr/lxportal/?menuno=2679 (Accessed: 17 March 2021).

[38] Agricultural Science Institute(ASI). Revised Korea Soil survey materials. No 13. 1992. Available at: https://lib.rda.go.kr/sear ch/mediaView.do?mets_no $=000000144158$ (Accessed: $22 \mathrm{Au}-$ gust 2021).

[39] Hyun BK, Jung SJ, Sonn YK, Park CW, Zhang YS, Song KC, et al. Comparison between methods for suitability classification of wild edible greens. Korean Journal of Soil Science and Fertilizer. 2010; 43: 696-704

[40] Jung JM, Lee WH, Jung SH. Insect distribution in response to climate change based on a model: review of function and use of CLIMEX. Entomological Research. 2016; 46: 223-235.

[41] NSR. Rural Development Administration. 2021. Available at: https://www.nongsaro.go.kr (Accessed: 3 August 2021).

[42] Fick SE, Hijmans RJ. WorldClim 2: new 1-km spatial resolution climate surfaces for global land areas. International Journal of Climatology. 2017; 37: 4302-4315.

[43] Stewart DPC, Cameron KC, Cornforth IS, Sedcole JR. Effects of spent mushroom substrate on soil physical conditions and plant growth in an intensive horticultural system. Soil Research. 1998; 36: 899-912.

[44] Agblor A, Scanlon MG. Effect of storage period, cultivar and two growing locations on the processing quality of French fried potatoes. American Journal of Potato Research. 2002; 79: 167172.

[45] Zhang YS, Han KH, Jung KH, Cho HR, Seo MJ, Sonn YK. Study on the standards of proper effective rooting depth for up- land crops. Korean Journal of Soil Science and Fertilizer. 2017; 50: $21-30$.

[46] The national of ATLAS of KOREAII. National Geography Information Institute (NGII). Ministry of land infrastructure and transport 2017. 2021. Available at: http://nationalatlas.ngii.go. kr/pages/page_526.php? (Accessed: 27 April 2021).

[47] Kim DH, Choi JY, Kwon SH, So JD, Kwon SG, Chung KY, et al. Water Use Efficiency of Soybean, Sorghum, Sesame with Different Groundwater Levels Using Lysimeter. Korean Journal of Soil Science and Fertilizer. 2018; 51: 339-352.

[48] Cho HJ, Hyun BK, Sonn YK, Park CW, Chun HC, Song KC, et al. A Study on soil suitability criteria for Liriopis platyphylla. Korean Journal of Soil Science and Fertilizer. 2013; 46: 542548.

[49] Kim IJ, Kim MJ, Nam SY, Yun T, Kim HS, Jong SK, et al. Growth characteristics and available component of Saururus chinensis Baill in different soil texture. Korean Journal of Medicinal Crop Science. 2006; 14: 143-147.

[50] Chun HC, Jung KY, Choi YD, Lee SH. Improved method of suitability classification for sesame (Sesamum indicum L.) cultivation in paddy field soils. Korean Journal of Soil Science and Fertilizer. 2017; 50: 520-529.

[51] Zare M, Farooque A, Abbas F, Zaman Q, Bos M. Trends in the variability of potato tuber yield under selected land and soil characteristics. Plant, Soil and Environment. 2019; 65: 111-117.

[52] Jasinski E, Morton D, DeFries R, Shimabukuro Y, Anderson L, Hansen M. Physical landscape correlates of the expansion of mechanized agriculture in Mato Grosso, Brazil. Earth Interactions. 2005; 9: 1-18.

[53] Haverkort AJ, de Ruijter EJ, van Evert EK, Conijn JG, Rutgers B. Worldwide sustainability hotspots in potato cultivation. 1. Identification and mapping. Potato Research. 2013; 56: 343353.

[54] Agricultural technology guide(potato). Rural Development Administration. 2020. Available at: https://www.nongsaro.go. $\mathrm{kr} /$ portal/ps/psb/psbx/cropEbookLst.ps?menuId=PS65290\&st $\mathrm{dPrdlstCode}=\mathrm{FC} \& \mathrm{sStdPrdlstCode}=\mathrm{FC} 050501 \#$ (Accessed: 10 November 2020).

[55] Jung SJ, Bark BS, Jang GS, Hyun BK, Rim SK. Suitability Class Criteria for Red Pepper with Respect to Soil Morphology and Physical Properties. Korean Journal of Soil Science and Fertilizer. 2004; 37: 336-340.

[56] Wang XL, Li FM, Jia Y, Shi WQ. Increasing potato yields with additional water and increased soil temperature. Agricultural Water Management. 2005; 78: 181-194.

[57] Struik PC. Chapter 18-Responses of the potato plant to temperature. Potato Biology and Biotechnology (pp. 367-393). Amsterdam, Netherlands: Elsevier Science. 2007.

[58] Berzitis EA, Minigan JN, Hallett RH, Newman JA. Climate and host plant availability impact the future distribution of the bean leaf beetle (Cerotoma trifurcata). Global Change Biology. 2014; 20: 2778-2792.

[59] Korea Meteorological Administration (KMA) open MET data portal. 2021. Available at: https://data.kma.go.kr/cmmn/main.d o (Accessed: 19 May 2021).

[60] Statistics Korea 2021. 2021. Available at: http://kostat.go.kr/por tal/korea/index.action (Accessed: 22 September 2021).

[61] Olivares B, Cortez A, Parra R, Lobo D, Rodríguez MF, Rey JC. Evaluation of agricultural vulnerability to drought weather in different locations of Venezuela. Revista De La Facultad De Agronomía De La Universidad Del Zulia. 2017; 34: 103-129.

[62] Caldiz DO, Gaspari FJ, Haverkort AJ, Struik PC. Agroecological zoning and potential yield of single or double cropping of potato in Argentina. Agricultural and Forest Meteorology. 2001; 109: 311-320.

[63] Choi SJ, Lee AS, Jeon SJ, Kim KD, Seo MC, Jung WS, et al. 
Estimating the yield of potato non-mulched using climatic elements. The Korean Journal of Crop Science. 2014; 59: 89-96.

[64] Lee AS, Choi SJ, Jeon SJ, Maeng JH, Kim JH, Kim IJ. Estimating the yield of marketable potato of mulch culture using climatic elements. The Korean Journal of Crop Science. 2016;
61: 70-77.

[65] Jeong JC, Yun YH, Chang DC, Park CS, Kim SY. Processing quality of potato (Solanum tuberosum L.) tubers as influenced by soil and climatic conditions. Korean Journal of Environmental Agriculture. 2003; 22: 261-265. 